\title{
Sildenafil Treatment Prevents Glomerular Hypertension and Hyperfiltration in Rats with Renal Ablation
}

\author{
Edilia Tapia $^{a}$ Laura G. Sanchez-Lozada ${ }^{a}$ Virgilia Soto $^{b}$ Andrés M. Manrique ${ }^{a}$ \\ Karla M. Ortiz-Vega ${ }^{a}$ José Santamaría ${ }^{a}$ Omar N. Medina-Campos ${ }^{c}$ Magdalena Cristóbal $^{\mathrm{a}}$ \\ Carmen Avila-Casado $^{b}$ José Pedraza-Chaverric ${ }^{c}$ Bernardo Rodríguez-Iturbe ${ }^{d}$ Martha Franco ${ }^{a}$ \\ Departments of a Nephrology and ${ }^{b}$ Pathology, Instituto Nacional de Cardiología Ignacio Chávez, and

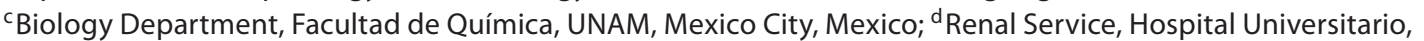 \\ Universidad del Zulia and Instituto Nacional de Investigaciones Científicas (IVIC)-Zulia, Maracaibo, Venezuela
}

\section{Key Words}

Glomerular hemodynamics - PDE5 inhibition • 5/6

nephrectomy $\cdot$ Sildenafil $\cdot$ Arteriolopathy $\cdot c G M P$

\begin{abstract}
Background: Sildenafil treatment ameliorates progressive renal injury resulting from extensive renal ablation; however, modifications induced by sildenafil in the glomerular hemodynamic pathophysiology of the remnant kidney have not been investigated. Aim: To determine the effects of sildenafil in the glomerular microcirculation and their relation to histological damage in the renal ablation model. Methods: Micropuncture studies were performed 60 days after 5/6 nephrectomy in rats that received no treatment, sildenafil $(5 \mathrm{mg} / \mathrm{kg} / \mathrm{day})$ and reserpine, hydralazine and hydrochlorothiazide to maintain the blood pressure within normal levels. Sham-operated rats untreated and treated with sildenafil served as controls. Results: As expected, renal ablation induced systemic and glomerular hypertension, hyperfiltration, proteinuria, glomerulosclerosis and tubulointerstitial inflammatory damage in the remnant kidney. Sildenafil treatment prevented single-nephron hyperfiltration and hypertension, suppressed renal arteriolar remodeling, ameliorated systemic hypertension and proteinuria, increased urinary excretion of $\mathrm{CGMP}$ and $\mathrm{NO}_{2}{ }^{-} / \mathrm{NO}_{3}{ }^{-}$, decreased oxidative
\end{abstract}

stress and improved histological damage in the remnant kidney. Normalization blood pressure with reserpine, hydralazine and hydrochlorothiazide did not modify glomerular hemodynamics, proteinuria or histological changes induced by renal ablation. Conclusions: Beneficial effects of sildenafil in the remnant kidney are associated with a reduction in the arteriolar remodeling, renal inflammatory changes and prevention of changes in the glomerular microcirculation.

Copyright $\odot 2012$ S. Karger AG, Basel

\section{Introduction}

Renal ablation results in hemodynamic changes in the remnant nephrons that engage the participation of proinflammatory and pro-fibrotic mechanisms that amplify nephron loss [1]. Oxidative stress and decreased nitric oxide (NO) availability play a critical role in the relentless process that characterizes chronic renal disease [2, 3], and improvement of renal damage may be obtained with the administration of the precursor of NO, L-arginine [4], as well as with compounds that activate intracellular pathways of cyclic $3^{\prime} 5^{\prime}$-guanosine monophosphate (cGMP) generation [5-7] that is the mediator of NO reactivity. Phosphodiesterase-5 (PDE5) is the most important degrading enzyme of cGMP in vascular smooth muscle

\section{KARGER \\ Fax +4161306 1234 \\ E-Mail karger@karger.ch}

www.karger.com
(C) 2012 S. Karger AG, Basel

$1420-4096 / 12 / 0354-0273 \$ 38.00 / 0$

Accessible online at:

www.karger.com/kbr
Martha Franco

Department of Nephrology

Instituto Nacional de Cardiología 'Ignacio Chávez'

Juan Badiano 1, Mexico City 14080 (Mexico)

Tel. +52 555573 6902, E-Mail marthafranco@lycos.com 
and its inhibition results in extended cGMP activity and increased vasodilatation. Recently, experiments from our group [7] and other laboratories [8-10] have shown that inhibition of PDE5 has beneficial effects in several models of chronic kidney disease, but the specific protective mechanisms resulting from increased cGMP availability in the kidney have not been fully elucidated.

Improvement of the remnant kidney nephropathy by sildenafil administration [7] may result from reduction of renal hypoxia and oxidative stress-induced interstitial inflammation [11, 12]. In addition, sildenafil has a direct inhibitory effect on the proliferation of vascular smooth muscle cells $[13,14]$, an effect that is central to its beneficial effects in pulmonary hypertension. Similar antiproliferative and anti-inflammatory effects in glomerular arterioles may prevent the loss of autoregulatory capacity that leads to glomerulosclerosis in the renal ablation nephropathy $[1,12,15]$. However, direct effects of NO in glomerular hemodynamics include preglomerular vasodilatation [15] and increased cGMP availability resulting from PDE5 inhibition would be expected to aggravate, rather than improve, the glomerular hypertension and hyperfiltration that triggers the progressive glomerulosclerosis in the remnant kidney.

The present studies were designed to investigate if sildenafil administration results in renoprotective modifications in the glomerular hemodynamic changes that trigger the progressive damage of the remnant kidney after $5 / 6$ nephrectomy in rats.

\section{Methods}

All animal procedures were performed in accordance to the Mexican Federal Regulation for animal experimentation and care (NOM-062-ZOO-2001) and were approved by the Bioethics and Investigation Committees of Instituto Nacional de Cardiología Ignacio Chávez. Sildenafil citrate was purchased from Pfizer (Mexico).

\section{Experimental Design}

Studies were carried out in male Wistar rats weighing 250$300 \mathrm{~g}$ at the beginning of the experiment. All surgical procedures and micropuncture studies were done under general anesthesia (sodium pentobarbital $30 \mathrm{mg} / \mathrm{kg}$ intraperitoneally). Rats were subjected to surgical $5 / 6 \mathrm{Nx}$ or sham operations, and five experimental groups were studied 60 days after surgery: (1) Sham-operated group $(n=9)$, consisting of rats that received no treatment; (2) Sham+Sil group $(n=8)$, consisting of sham-operated rats that received $5 \mathrm{mg} / \mathrm{kg}$ sildenafil daily by gastric gavage started the day after surgery; (3) $5 / 6 \mathrm{Nx}$ group $(\mathrm{n}=9$ ), consisting of rats with $5 / 6$ nephrectomy and received no additional treatment; (4) $5 / 6 \mathrm{Nx}+\mathrm{Sil}$ group $(n=10)$, consisting of rats with $5 / 6$ nephrectomy and received sildenafil daily by gastric gavage starting the day after sur- gery, and (5) 5/6Nx+TRX group ( $n=8$ ), consisting of rats with $5 / 6$ nephrectomy and received reserpine $(5 \mathrm{mg} / \mathrm{l})$, hydralazine $(80$ $\mathrm{mg} / \mathrm{l})$, and hydrochlorothiazide $(25 \mathrm{mg} / \mathrm{l})$ in the drinking water starting $48 \mathrm{~h}$ after surgery to maintain normal blood pressure in rats with renal ablation [16].

24-hour urine collections for proteinuria were obtained at baseline and every 2 weeks during the study, before the micropuncture experiments.

Systolic blood pressure (SBP) was measured in conscious restrained rats by tail-cuff plethysmography (XBP-1000; Kent Scientific, Torrington, Conn., USA). Rats were preconditioned twice before SBP was measured at basal period, and every 2 weeks for the rest of the study as described in earlier studies [12]. In addition to tail-cuff plethysmography, blood pressure was also determined by direct intra-arterial measurement through the experiment by a catheter placed in the femoral artery during the micropuncture experiments (see later).

\section{Renal Ablation}

Right nephrectomy and selective infarction of approximately two-thirds of the left kidney by ligation of branches of the renal artery were done in a single procedure. The sham operation consisted of manipulation of the kidneys and renal pedicle.

Urinary cGMP and Nitrate/Nitrite $\left(\mathrm{NO}_{3}{ }^{-} / \mathrm{NO}_{2}{ }^{-}\right)$Excretion

Urinary cGMP excretion was measured in 24-hour urine collections obtained before micropuncture studies, using a commercially available ELISA kit (Direct cGMP Enzyme Immunoassay Kit; Assay Diagnostics, Inc., Ann Arbor, Mich., USA). The excretion of $\mathrm{NO}_{3}{ }^{-} / \mathrm{NO}_{2}{ }^{-}$was obtained by reduction $\mathrm{NO}_{3}{ }^{-}$to $\mathrm{NO}_{2}{ }^{-}$ and total $\mathrm{NO}_{2}{ }^{-}$was measured using the Griess reagent as described earlier [17].

\section{Micropuncture Studies}

Micropuncture studies were performed 60 days after the surgical procedure (5/6 nephrectomy or sham) under sodium pentobarbital anesthesia (30 mg/kg body weight) intraperitoneally with supplementary doses as required. Micropuncture methodology has been previously described [12] briefly; the rats were placed on a temperature-regulated table, at $37^{\circ} \mathrm{C}$. Polyethylene tubing was used to catheterize the trachea both jugular veins, femoral arteries and the left ureter. The left kidney was exposed, through a lumbar incision, placed in a Lucite holder and sealed, covering the kidney surface with $0.9 \%$ saline solution. One femoral artery catheter was used for blood sampling and the other for monitoring mean arterial pressure (MAP) with a pressure transducer (Model p23 Db; Gould, San Juan, P.R., USA) and recorded on a polygraph (Grass Instruments, Quincy, Mass., USA). During the surgery, rats received a $6 \%$ albumin infusion ( $1 \%$ of body weight), through a jugular catheter. Immediately after a bolus injection of $100 \mathrm{mg}$ of polyfructosan, an infusion of $5 \%$ polyfructosan in Ringer solution was started at a rate of $2.2 \mathrm{ml} / \mathrm{h}$ (Inutest; Fresenius Pharma, Linz, Austria). $60 \mathrm{~min}$ were allowed for equilibration before the studies were done. Sampling blood was simultaneously replaced by an equal volume of resuspended red blood cells in saline solution. At the end of the experiment the kidneys were removed and weighed.

Samples of proximal tubule fluid were obtained from seven different nephrons after inserting an oil block with a micropipette for determination of flow rate and polyfructosan concentration to calculate single-nephron glomerular filtration rate (SNGFR). 
Polyfructosan was measured in plasma and urine samples to calculate whole-kidney GFR. Using a continuous-recording servo-null micropipette transducer (Servo Nulling Pressure System, Instrumentation for Physiology and Medicine, Inc., Calif., USA), intratubular hydrostatic pressure was measured in additional proximal tubules under free flow conditions and after stopping tubular flow with an oil block (stop flow pressure); hydrostatic pressure was also measured in peritubular capillaries. Colloid osmotic pressure in glomerular capillaries was estimated from the protein concentration in blood taken from the femoral artery and in blood obtained by puncturing surface efferent arterioles [18].

\section{Analytical Procedures}

Polyfructosan concentrations in plasma and urine were determined by the anthrone method [19]. The volume of fluid collected from individual proximal tubules was estimated from the length of the fluid column in a constant bore capillary tube of known internal diameter. The concentration of polyfructosan in the tubular fluid was measured in triplicate by a microfluorometric method [20]. Protein concentrations were determined in efferent samples and femoral arterial blood plasma using a fluorometric method [21].

Urinary protein concentration was measured by precipitation with $12.5 \%$ trichloroacetic acid. Turbidity was determined and measuring at a wavelength of $595 \mathrm{~nm}$ using a Beckman spectrophotometer [22]. SNGFR, glomerular capillary hydrostatic pressure, single-nephron plasma flow, single-nephron glomerular blood flow, afferent an efferent resistances and ultrafiltration coefficient were calculated [18].

\section{Histological Analysis and Immunohistochemistry}

Paraffin-embedded sections stained with hematoxylin and eosin (HE), trichrome and periodic acid-Schiff reagent were examined in a blinded fashion. Arteriolar morphology was assessed by indirect peroxidase immunostaining for $\alpha$-smooth muscle actin (Dako Corp., Carpinteria, Calif., USA). Renal sections incubated with normal rabbit serum were used as negative controls. For each arteriole, the external outline and internal lumen (excluding endothelium) were identified; the total medial area was determined by computer image analysis in 10 arterioles in close proximity to the glomeruli in each remnant kidney section. The media/lumen ratio was calculated by the outline/inline ratio.

Tubulointerstitial fibrosis was evaluated in Masson's trichrome sections. 30 non-overlapping fields of cortex $(640 \times 477$ $\mathrm{mm}$ at $10 \times$ ) per biopsy were analyzed by light microscopy (Olympus BX51; Olympus American, New York, N.Y., USA) and captured with a digital video camera (CoolSnap Pro; Media Cybernetics, Madison, Wisc., USA). Positive blue color areas (excluding glomeruli, and vessels) were analyzed using Image-Pro-Plus 5.0 (Media Cybernetics). The extension of positive areas (30 microscopic fields per biopsy) was expressed as a fraction of the total tubulointerstitial area examined.

Tubulointerstitial cellular infiltration was studied in HE sections. The number of cells by field was evaluated as positive cells per $\mathrm{mm}^{2}$.

Glomerular sclerosis was determined as previously described [7]: grade $0=$ no sclerosis; grade $1=<25 \%$ of the glomerulus; grade $2=25-50 \%$ of the glomerulus; grade $3=>50-75 \%$ of the glomerulus, and grade $4=>75-100 \%$ of the glomerulus. The score of a biopsy was calculated with the equation $[(1 \times$ number glo- meruli grade 1$)+(2 \times$ number glomeruli grade 2$)+(3 \times$ number glomeruli grade 3$)+(4 \times$ number glomeruli grade 4$)] \times$ $100 /$ total number of glomeruli examined.

\section{Western Blot}

Nitrotyrosine abundance in the experimental groups was evaluated by Western blot as described in previous communications [23] using anti-nitrotyrosine (Biomol Labs) and $\beta$-actin (Sigma) antibodies. Secondary antibody was horseradish peroxidase-conjugated rabbit anti-mouse IgG antibody (Stressgen). Peroxidase activity was developed using 3,3-diaminobenzidine, and then protein expression levels were quantified using the Image-J program (NIH, Bethesda, Md., USA) and expressed as arbitrary optical density units relative to $\beta$-actin blots.

\section{Statistical Analysis}

Data are presented as mean \pm SD. Differences between groups were evaluated by multiple comparison ANOVA tests with Tukey post-tests and the nitrotyrosine results were analyzed with Kuskal-Wallis test with Dunn's post-test, using a commercially available statistical package (GraphPad Prism 4.0, La Jolla, Calif., USA). Two-tailed $\mathrm{p}<0.05$ was considered significant.

\section{Results}

Rats in the experimental groups had comparable weight, blood pressure and urinary protein excretion in the baseline studies and had comparable weights at the end of the experiment: Sham $=393 \pm 11 \mathrm{~g}$; Sham + Sil $=$ $403.0 \pm 12 \mathrm{~g} ; 5 / 6 \mathrm{Nx}=392.0 \pm 19.43 \mathrm{~g} ; 5 / 6 \mathrm{Nx}+\mathrm{Sil}=362.2$ $\pm 8.05 \mathrm{~g}$, and $5 / 6 \mathrm{Nx}+\mathrm{TRX}=387.63 \pm 17.39 \mathrm{~g}$. Rats with renal ablation developed severe systemic hypertension: SBP increased from $120 \pm 2.63$ to $181.8 \pm 5.7 \mathrm{~mm} \mathrm{Hg}$ in 60 days. Treatment with sildenafil was associated with a less pronounced increment in blood pressure (fig. 1a). Essentially similar blood pressure levels were obtained with tail-cuff determinations and with intra-arterial measurements (fig. 1b).

Remnant kidney weight 60 days after renal ablation in untreated $5 / 6 \mathrm{Nx}$ rats $(2.05 \pm 0.10 \mathrm{~g})$ and the remnant weight in the $5 / 6 \mathrm{Nx}+\mathrm{TRX}$ rats $(2.10 \pm 0.10 \mathrm{~g})$ exceeded the weight of the left kidney in the sham-operated controls $(1.58 \pm 0.05 \mathrm{~g}, \mathrm{p}<0.01)$, as expected from the hypertrophy resulting from renal ablation. In contrast, remnant kidney hypertrophy in the sildenafil-treated rats was significantly reduced $(1.27 \pm 0.01 \mathrm{~g}, \mathrm{p}<0.001 \mathrm{vs.} 5 / 6 \mathrm{Nx})$ and was similar versus left kidney of Sham group $(p=N S)$. Subtotal renal ablation was followed by the characteristic progressive elevation proteinuria. As shown in figure 1c, the urinary protein excretion in the rats that received sildenafil treatment was reduced by approximately twothirds by sildenafil $(\mathrm{p}<0.001)$ and remained at essentially steady levels 2 months after 5/6 nephrectomy. 
Fig. 1. SBP obtained by serial tail cuff determinations (a) and invasive intra-arterial measurements during the experiment (b). Proteinuria (c), GFR (d), urinary cGMP (e) and $\mathrm{NO}_{3}{ }^{-} / \mathrm{NO}_{2}{ }^{-}(\mathbf{f})$ in the experimental and control groups are also shown. ${ }^{*} \mathrm{p}<0.05$ vs. Sham; ${ }^{\circ} \mathrm{p}<0.05$ vs. $5 / 6 \mathrm{Nx}$; $+\mathrm{p}<0.05$ vs. Sham+Sil; ${ }^{\#} \mathrm{p}<0.01$ vs. $5 / 6 \mathrm{Nx}+\mathrm{Sil}$.

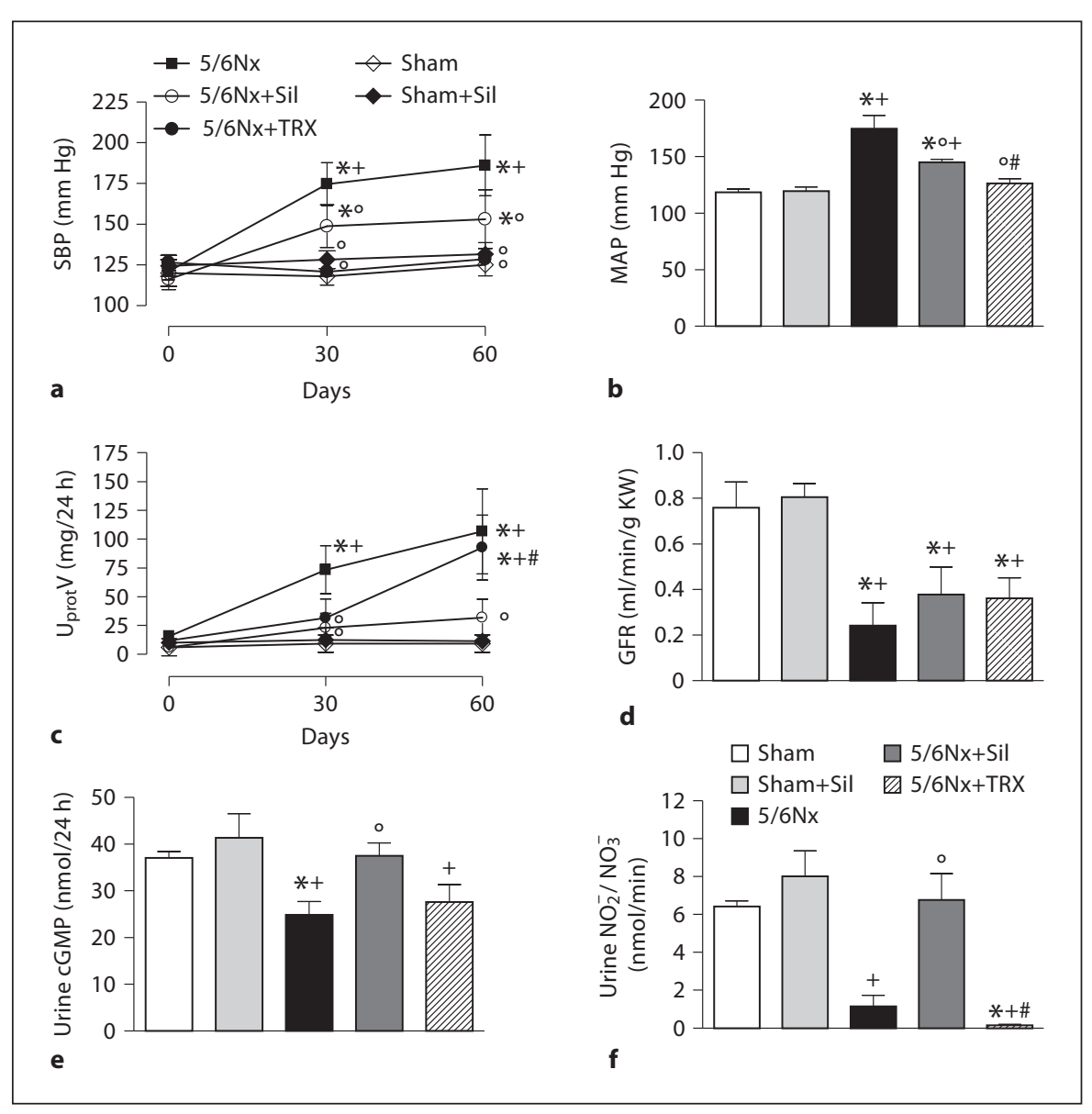

The GFR is shown in figure $1 \mathrm{~d}$. Rats that had 5/6 nephrectomy had reduced total GFR that was more depressed in the untreated rats at the end of the experiment. Since the SNGFR was $66 \%$ lower in the remnant kidney of rats treated with sildenafil than in the remnant kidney of untreated rats (see later, fig. 2e), the number of functioning (non-hyperfiltering) nephrons must have been at least that much higher in the $5 / 6 \mathrm{Nx}+$ Sil group.

\section{Urinary cGMP and Nitrate/Nitrite Excretion}

Urinary cGMP and $\mathrm{NO}_{2}{ }^{-} / \mathrm{NO}_{3}{ }^{-}$excretion were reduced in the untreated rats with $5 / 6 \mathrm{Nx}$ and increased by sildenafil treatment $(\mathrm{p}<0.05)$ to levels similar to those found in sham-operated rats (fig. 1e, f).

\section{Micropuncture Studies}

The findings in the micropuncture studies 60 days after $5 / 6 \mathrm{Nx}$ are shown in figure 2 . The most relevant changes observed in the sildenafil-treated group were the normalization of $\mathrm{P}_{\mathrm{GC}}$ (fig. 2a) and SNGFR (fig. 2e) resulting from a significant increase in the preglomerular tone evidenced by the rise in afferent arteriolar resistance (fig. 2c). No significant differences were observed in the ultrafiltration coefficient $\left(\mathrm{K}_{\mathrm{f}}\right.$, range $0.0319-0.0350 \mathrm{nl} / \mathrm{s} / \mathrm{mm} \mathrm{Hg}$ ), afferent oncotic pressure (range 12.14-18.12 mm Hg), efferent oncotic pressure (range $23.45-24.46 \mathrm{~mm} \mathrm{Hg}$ ) nor in singlenephron filtration fraction (range 0.29-0.33).

\section{Histological Analysis}

Afferent arteriolar hypertrophy was a characteristic found in the remnant kidney; in contrast, sildenafil prevented the hypertrophy of the afferent arteriole (fig. 3). Figure 4 shows that sildenafil treatment reduced glomerulosclerosis, tubulointerstitial inflammation and fibrosis in the remnant kidney.

\section{Oxidative Stress in the Remnant Kidney}

Evaluation of the oxidative stress in the remnant kidney was done by assessing renal nitrotyrosine abundance by Western blot. Results are shown in figure 5 that dem- 
Fig. 2. Micropuncture studies at 60 days after surgery in the experimental and control groups. Glomerular capillary pressure (a), glomerular plasma flow (b), afferent resistance (c), efferent resistance (d), SNGFR (e) are shown. Ultrafiltration coefficient $\left(\mathrm{K}_{\mathrm{f}}\right)$ and plasma oncotic pressure (afferent and efferent) and single-nephron filtration fraction were not significantly different in the experimental groups. ${ }^{*} \mathrm{p}<$ 0.05 vs. Sham; o $\mathrm{p}<0.05$ vs. $5 / 6 \mathrm{Nx}$; ${ }^{+} \mathrm{p}<0.001$ vs. Sham+Sil; ${ }^{\#} \mathrm{p}<0.01$ vs. $5 / 6 \mathrm{Nx}+$ Sil.

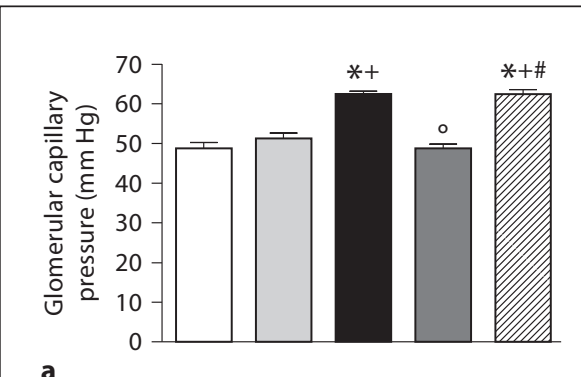

a

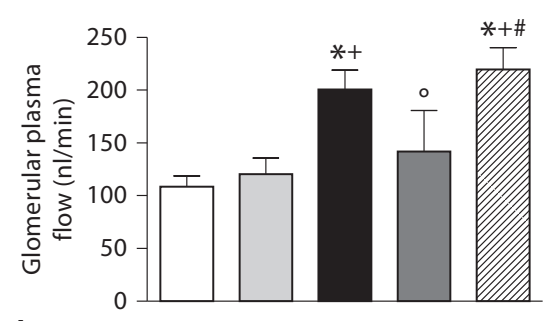

b

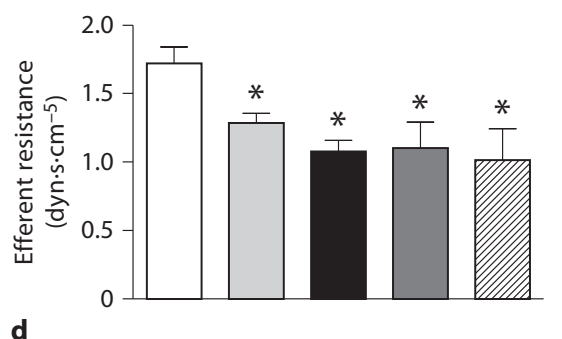

C
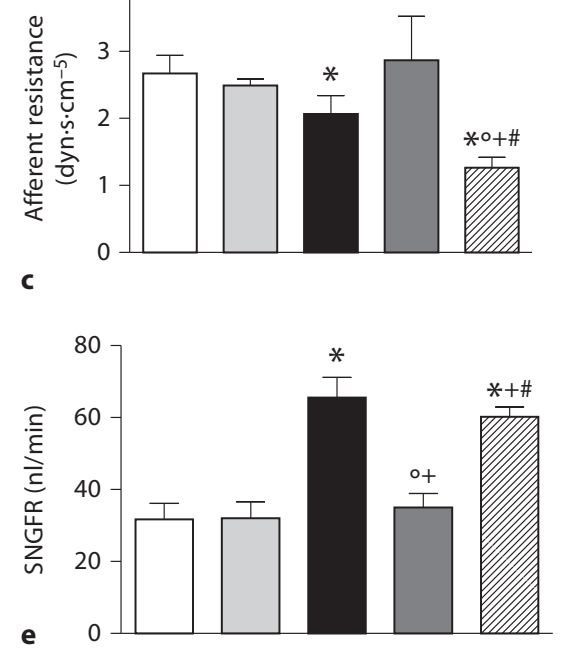

onstrate that the remnant kidney has increased nitrotyrosine expression and sildenafil treatment significantly $(p<0.001)$ reduces this marker of oxidative stress.

\section{Discussion}

The present studies found that the administration of sildenafil to rats with renal ablation results in prevention of glomerular hypertension and hyperfiltration, suppression of vascular smooth muscle cell proliferation in the glomerular arterioles of the remnant kidney and amelioration in histological and functional damage in the remnant kidney. As determined by tail-cuff plethysmography as well as by direct intra-arterial determinations (fig. 1a, b), sildenafil treatment ameliorated hypertension, an effect that is observed in rats treated chronically with this drug $[7,24]$ but not regularly in short-term studies [2527]. To determine whether reduction of the blood pressure would by itself play a role in the beneficial effects of sildenafil, we studied the rats of the TRX group that de- spite normalization of blood pressure had no improvement in the remnant kidney glomerular hemodynamics or histological damage.

The reduction of inflammation (fig. 4) and the antiproliferative effects on vascular smooth muscle cells (fig. 3) are not unexpected consequences of sildenafil treatment. The suppression of the inflammation in the remnant kidney is likely related to the reduction of renal hypoxia and oxidative stress since sildenafil inhibits superoxide generation [28] and increases its degradation by a superoxide dismutase mimetic effect [29]. Consistent with this interpretation is the demonstration that nitrotyrosine abundance in the kidney, a marker for oxidative stress that is increased in the remnant kidney, is suppressed by sildenafil treatment (fig. 5). Enhanced NO activity downregulates the expression of leukocyte adhesion molecules thereby opposing migration and renal infiltration of inflammatory cells and, in addition, it exerts antithrombotic effects that may help to keep patent renal microvasculature [30]. The antiproliferative effects of sildenafil in vascular smooth muscle cells are well recognized [14] and 

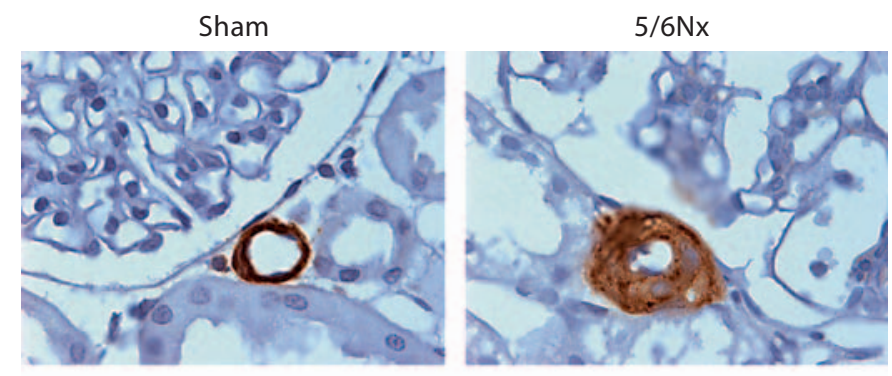

$5 / 6 \mathrm{Nx}+\mathrm{Sil}$
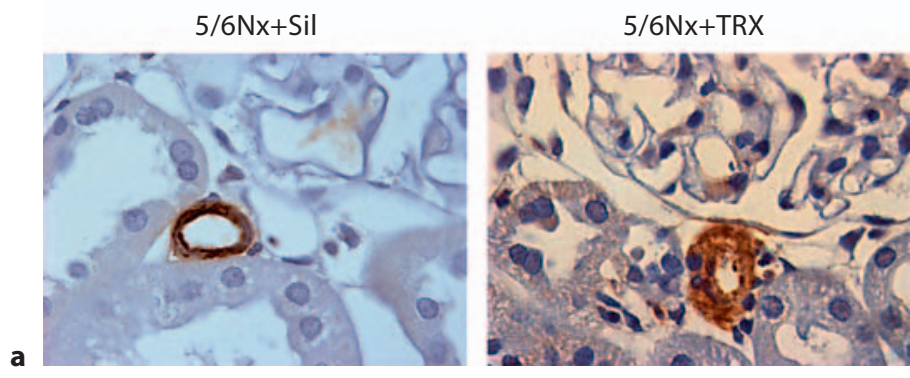

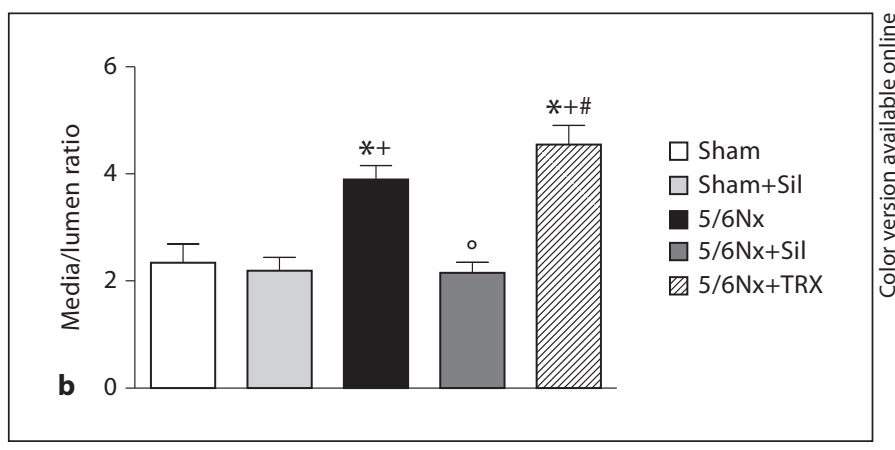

Fig. 3. Microphotographs (a) showing the afferent arteriole smooth muscle proliferation in experimental and control groups. Media/lumen ratios are shown in $\mathbf{b} .{ }^{*} \mathrm{p}<0.01 \mathrm{vs}$. Sham; ${ }^{\circ} \mathrm{p}<0.001$ vs. $5 / 6 \mathrm{Nx} ;{ }^{+} \mathrm{p}<0.01$ vs. Sham + Sil. ${ }^{\#} \mathrm{p}<0.001$ vs. $5 / 6 \mathrm{Nx}+$ Sil.
Fig. 4. Glomerulosclerosis score (a), interstitial inflammation (b) and interstitial fibrosis (c) in the experimental and control groups. ${ }^{*} \mathrm{p}<0.05$ vs. Sham; ${ }^{\circ} \mathrm{p}<0.05$ vs. $5 / 6 \mathrm{Nx} ;{ }^{+}$p 0.001 vs. Sham + Sil; ${ }^{\#} \mathrm{p}<0.01$ vs. $5 / 6 \mathrm{Nx}+\mathrm{Sil}$.

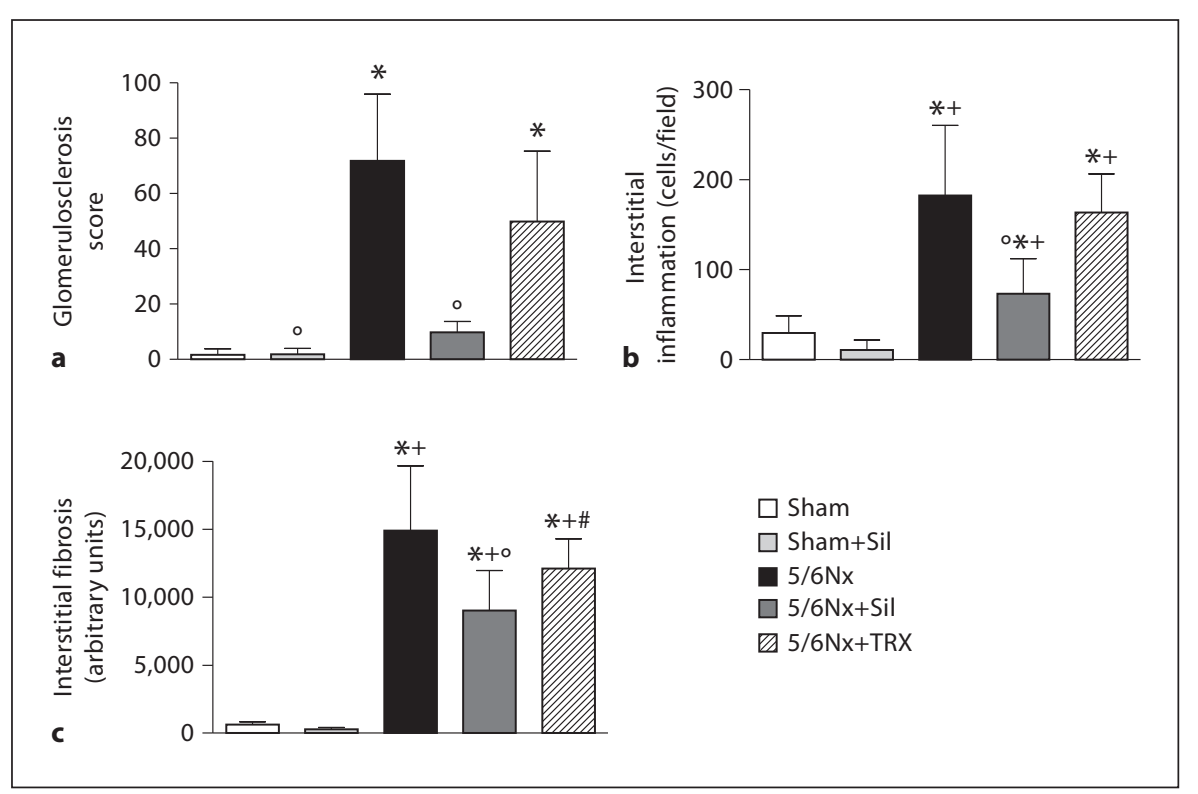

result from a reduction in cyclin D1 and cyclin-dependent kinase 4 (CDK4) activities [13], activation of MAPK p42/44 and subsequent p21 upregulation [31] and blockade of PKG- and PKA-mediated pathways [14].

In contrast to the expected beneficial effects of sildenafil on renal inflammation and arterial remodeling, the direct effects of increased NO availability on the glomerular circulation are opposed to those found in the present studies. NO causes preglomerular vasodilatation [30], and therefore, inhibition of cGMP degradation would be ex- pected to aggravate, rather than reduce, glomerular hypertension in the remnant kidney. Several considerations may explain the discrepancy between the expected and the found glomerular hemodynamic changes. First is the fact that the studies that examined NO effects on renal microcirculation [15] derived their conclusions from contrasting the vasoconstriction induced by inhibition of NO synthesis with preexisting baseline levels; therefore, enhancement of NO activity by PDE5 inhibition has not been critically analyzed. Second is the consideration that PDE5 in- 


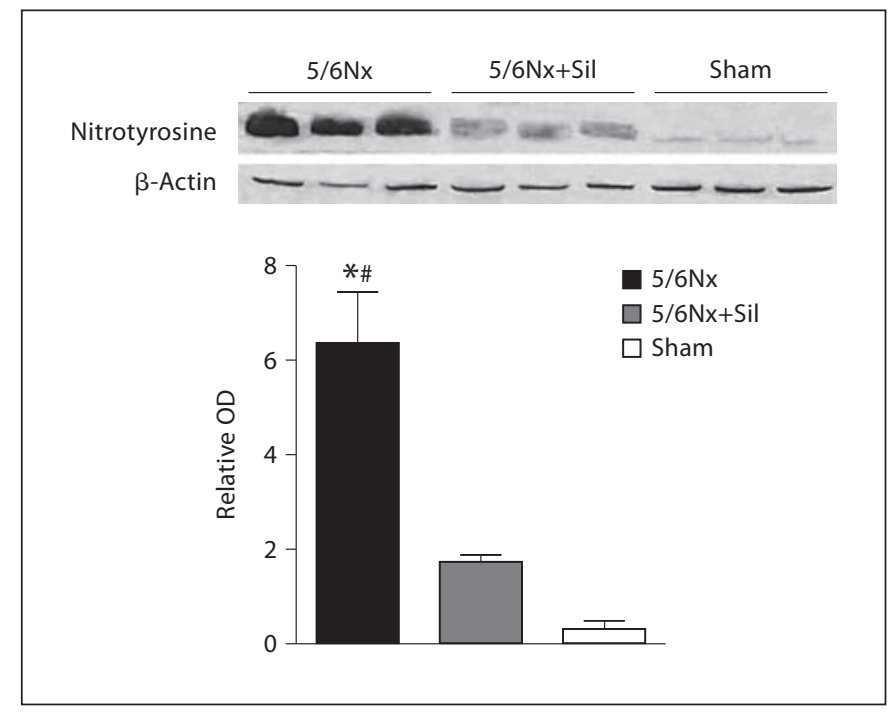

Fig. 5. Western Blot determination of the renal nitrotyrosine abundance in the remnant kidney and the effects induced by sildenafil treatment. Sildenafil (5 $\mathrm{mg} / \mathrm{kg} /$ day) was administered after renal ablation and studies correspond to kidney samples obtained 60 days after renal ablation. ${ }^{*} \mathrm{p}<0.001$ vs. Sham; ${ }^{*} \mathrm{p}<0.001$ vs. $5 / 6 \mathrm{Nx}$.

hibition does not necessarily increase NO concentration above normal; rather it extends the effects of generated NO. The urinary NO levels observed in the sildenafiltreated group (fig. 3, discussed later) are comparable to those in sham-operated animals, and while this would represent a relative increment for a remnant kidney, it may not be of sufficient magnitude to override a protective afferent vasoconstriction. In addition, since urinary $\mathrm{NO}_{2}{ }^{-}$$\mathrm{NO}_{3}{ }^{-}$represents $\mathrm{NO}$ produced in the whole circulatory system, and sildenafil partially ameliorated hypertension induced by $5 / 6 \mathrm{Nx}$, shear stress could contribute to the increased nitrites excretion by the kidney. Furthermore, some effects of sildenafil actually favor the preservation of glomerular hemodynamics. Among such effects are suppression of arteriolar remodeling [12] and reduction of cytokine-induced impairment of autoregulation [32]. Finally, there is the possibility that reduction in oxidative stress and antiproliferative and anti-inflammatory effects of sildenafil discussed earlier prevent or suppress the glomerular hemodynamic changes in the remnant kidney that would otherwise result from direct effects of PDE5 inhibition in renal microcirculation. This possibility would imply that non-hemodynamic events triggered by renal mass reduction would have a primary and pivotal role in the development glomerular hyperfiltration.
Urinary excretion of cGMP and NO were reduced by $5 / 6 \mathrm{Nx}$ and increased by sildenafil treatment to levels comparable to the sham-operated controls. As discussed earlier, an increment in NO production is not expected from PDE5 inhibition and the urinary values of NO are within normal range; however, the values observed in the sildenafil-treated group actually represent an increment relative to the remnant renal mass. While it is conceivable that systemic endothelial damage resulting from hypertension may increase $\mathrm{NO}$ release that is ultimately cleared by the kidney, it appears more reasonable to attribute the increment in urinary NO to sildenafil treatment. Sildenafil-induced increment in NO production has been found in specific experimental conditions, for instance in cardiac myocytes subjected to ischemia and reoxygenation, in which sildenafil enhances $\mathrm{mRNA}$ and protein content of inducible NOS and endothelial NOS [33] and in the ischemia-reperfusion model of renal injury, in which sildenafil attenuates the renal damage and increases the expression of inducible and endothelial NO synthase as well as phosphorylation of ERK and reduction in BAX/ BCL2 ratio [34]. Attenuation of renal damage by sildenafil treatment could also induce a relative increment of $\mathrm{NO}$ in the remnant kidney. In addition, the finding of increased urinary NO may also be the result of reduction in oxidative stress-induced $\mathrm{NO}$ consumption in the remnant kidney as a consequence of reduction in the generation and increase in disposal of superoxide radicals $[1,23$, 28].

In conclusion, sildenafil treatment results in prevention of the hemodynamic changes in glomerular microcirculation associated with renal mass reduction. Arteriolar remodeling, renal inflammatory injury and functional deterioration in the remnant kidney are ameliorated by sildenafil treatment. Potential clinical benefits of sildenafil therapy deserve further study.

\section{Acknowledgments}

We thank to B. Chávez-Rentería for technical assistance. This study was supported by grant 52145/66780 (to E. Tapia) from the National Council of Science and Technology (CONACyT), Mexico, and a Research Career Grant from the Instituto Venezolano de Investigaciones Científicas, Venezuela (to B. RodríguezIturbe).

\section{Disclosure Statement}

None of the authors have any conflicts of interest to disclose. 


\section{References}

$>1$ Rodríguez-Iturbe B, Garcia-Garcia G: The role of tubulointerstitial inflammation in the progression of chronic renal failure. Nephron Clin Pract 2010;116:C81-C88.

$>2$ Fine LG, Norman JT: Chronic hypoxia as a mechanism of progression of chronic kidney diseases: from hypothesis to novel therapeutics. Kidney Int 2008;74:867-872.

-3 Vaziri ND, Ni Z, Oveisi F, Liang K, Pandian $\mathrm{R}$ : Enhanced nitric oxide inactivation and protein nitration by reactive oxygen species in renal insufficiency. Hypertension 2002; 39:135-141.

4 Ingram A, Parbtani A, Thai K, Ly H, Shankland SJ, Morrissey G, Scholey JW: Dietary supplementation with L-arginine limits cell proliferation in the remnant glomerulus. Kidney Int 1995;48:1857-1865.

$>5$ Hohenstein B, Daniel C, Wagner A, Stasch JP, Hugo C: Stimulation of soluble guanylyl cyclase inhibits mesangial cell proliferation and matrix accumulation in experimental glomerulonephritis. Am J Physiol Renal Physiol 2005;288:F685-F693.

6 Wang Y, Krämer S, Loof T, Martini S, Kron S, Kawachi H, Shimizu F, Neumayer HH, Peters $\mathrm{H}$ : Stimulation of soluble guanylate cyclase slows progression in anti-Thyl-induced chronic glomerulosclerosis. Kidney Int 2005;68:47-61.

7 Rodríguez-Iturbe B, Ferrebuz A, Vanegas V, Quiroz Y, Espinoza F, Pons H, Vaziri ND: Early treatment with cGMP phosphodiesterase inhibitor ameliorates progression of renal damage. Kidney Int 2005;68:2131-2142.

-8 Aboutabl ME, Raafat M, Maklad YA, Kenawy SA, El Din AG: Sildenafil augments the beneficial hemodynamic and histopathological effects of amlodipine in nitric oxide-deficient hypertensive rats: role of nitric oxidecyclic GMP pathway. Pharmacol Res 2008; 57:456-463.

$>9$ Hosogai N, Tomita M, Hamada K, Ogawa T, Hirosumi J, Manda T, Mutoh S: Phosphodiesterase type 5 inhibition ameliorates nephrotoxicity induced by cyclosporin A in spontaneous hypertensive rats. Eur J Pharmacol 2003;477:171-178.

$>10$ Jeong KH, Lee TW, Ihm CG, Lee SH, Moon JY, Lim SJ: Effects of sildenafil on oxidative and inflammatory injuries of the kidney in streptozotocin-induced diabetic rats. Am J Nephrol 2009;29:274-282.

-11 Remuzzi G, Zoja C, Gagliardini E, Corna D, Abbate M, Benigni A: Combining an antiproteinuric approach with mycophenolate mofetil fully suppresses progressive nephropathy of experimental animals. J Am Soc Nephrol 1999;10:1542-1549.
12 Tapia E, Franco M, Sánchez-Lozada LG, Soto V, Avila-Casado C, Santamaría J, Quiroz Y, Rodríguez-Iturbe B, Herrera-Acosta J: Mycophenolate mofetil prevents arteriolopathy and renal injury in subtotal ablation despite persistent hypertension. Kidney Int 2003;63: 994-1002.

13 Fukumoto S, Koyama H, Hosoi M, Yamakawa K, Tanaka S, Morii H, Nishizawa Y: Distinct role of cAMP and cGMP in the cell cycle control of vascular smooth muscle cells: cGMP delays cell cycle transition through suppression of cyclin D1 and cyclin-dependent kinase 4 activation. Circ Res 1999;85: 985-991.

14 Tantini B, Manes A, Fiumana E, Pignatti C, Guarnieri C, Zannoli R, Branzi A, Galié N: Antiproliferative effect of sildenafil on human pulmonary artery smooth muscle cells. Basic Res Cardiol 2005;100:131-138.

$>15$ Raij L, Baylis C: Glomerular actions of nitric oxide. Kidney Int 1995;48:20-32.

16 Anderson S, Rennke HG, Brenner BM: Antihypertensive therapy must control glomerular hypertension to limit glomerular injury. J Hypertens Suppl 1986;4:S242-S244.

17 Bartholomew B: A rapid method for the assay of nitrate in urine using the nitrate reductase enzyme of Escherichia coli. Food Chem Toxicol 1984;22:541-543.

18 Baylis C, Deen WM, Myers BD, Brenner BM: Effects of some vasodilator drugs on transcapillary fluid exchange in renal cortex. Am J Physiol 1976;230:1148-1158.

19 Davidson WD, Sackner MA: Simplification of the anthrone method for the determination of inulin in clearance studies. J Lab Clin Med 1963;62:351-356.

20 Vurek G, Pegram S: Fluorometric method for the determination of nanogram quantities of inulin. Anal Biochem 1966;16:409-419.

21 Viets JW, Deen WM, Troy JL, Brenner BM: Determination of serum protein concentration in nanoliter blood samples using fluorescamine or 9-phthalaldehyde. Anal Biochem 1978;88:513-521.

22 Henry RJ, Segalove M, Sobel C: Turbidimetric determination of proteins with sulfosalicylic and trichloroacetic acids. Proc Soc Exp Biol Med 1956;92:748-751.

23 Kim HJ, Vaziri ND, Norris K, An WF, Quiroz Y, Rodriguez-Iturbe B: High-calorie diet with moderate protein restriction prevents cachexia and ameliorates oxidative stress, inflammation and proteinuria in experimental chronic kidney disease. Clin Exp Nephrol 2010;14:536-547.

24 Yaguas K, Bautista R, Quiroz Y, Ferrebuz A, Pons H, Franco M, Vaziri ND, RodriguezIturbe B: Chronic sildenafil treatment corrects endothelial dysfunction and improves hypertension. Am J Nephrol 2010;31:283291.
25 Gardiner SM, March JE, Kemp PA, Ballard SA, Hawkeswood E, Hughes B, Bennett T: Hemodynamic effects of phosphodiesterase 5 and angiotensin-converting enzyme inhibition alone or in combination in conscious SHR. J Pharmacol Exp Ther 2005;312:265271.

26 Rossoni G, Manfredi B, De Gennaro V, Berti M, Guazzi M, Berti F: Sildenafil reduces LNAME-induced severe hypertension and worsening of myocardial ischaemia-reperfusion damage in the rat. Br J Pharmacol 2007; 150:538-540.

-27 Behr-Roussel D, Oudot A, Compagnie S, Gorny D, LeCoz O, Wayman C, Alexandre L, Giuliano F: Impact of a long-term sildenafil treatment on pressor response in conscious rats with insulin resistance and hypertriglyceridemia. Am J Hypertens 2008;21: 1258-1263.

28 Koupparis AJ, Jeremy JY, Muzaffar S, Persad R, Shukla N: Sildenafil inhibits the formation of superoxide and the expression of GP47 NAD $[\mathrm{P}] \mathrm{H}$ oxidase induced by the thromboxane $\mathrm{A}_{2}$ mimetic, $\mathrm{U} 46619$, in corpus cavernosal smooth muscle cells. BJU Int 2005;96:423-427.

29 Fernandes MA, Marques RJ, Vicente JA, Santos MS, Monteiro P, Moreno AJ, Custodio JB: Sildenafil citrate concentrations not affecting oxidative phosphorylation depress $\mathrm{H}_{2} \mathrm{O}_{2}$ generation by rat heart mitochondria. Mol Cell Biochem 2008;309:77-85.

30 Ito S, Carretero OA, Abe K: Role of nitric oxide in the control of glomerular microcirculation. Clin Exp Pharmacol Physiol 1997;24: 578-581.

31 Stotz WH, Li D, Johns RA: Exogenous nitric oxide upregulates $\mathrm{p} 21$ (waf1/cip1) in pulmonary microvascular smooth muscle cells. J Vasc Res 2004;41:211-219.

32 Sharma K, Cook A, Smith M, Valancius C, Inscho EW: TGF- $\beta$ impairs renal autoregulation via generation of ROS. Am J Physiol Renal Physiol 2005;288:F1069-F1077.

33 Das A, Xi L, Kukreja RC: Phosphodiesterase-5 inhibitor sildenafil preconditions adult cardiac myocytes against necrosis and apoptosis. Essential role of nitric oxide signaling. J Biol Chem 2005;280:12994-12955.

>34 Choi DE, Jeong JY, Lim BJ, Chung S, Chang YK, Lee SJ, Na KR, Kim SY, Shin YT, Lee KW: Pretreatment of sildenafil attenuates ischemia-reperfusion renal injury in rats. Am J Physiol Renal Physiol 2009;297:F362-F370. 